\title{
Characterization of suicidal behavior among children in a depressive episode: case series study
}

\author{
Caracterização do comportamento suicida em crianças em episódio depressivo: \\ estudo de série de casos
}

\begin{abstract}
Ana Luiza Pereira de Souza, ${ }^{1}$ Beatriz Werkhaizer Segolin, ${ }^{1}$ Paula Bedim Pessanha, ${ }^{1}$ Tânia Queiroz de Araújo Abreu, ${ }^{1}$

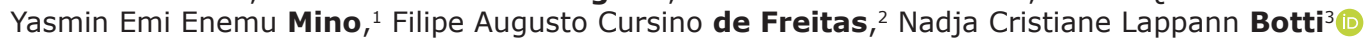

\begin{abstract}
Introduction: Child suicidal behavior is related to specific childhood variations, constituting risk factors, including predisposing factors, internal factors, and environmental factors.

Objective: To characterize suicidal behavior among children aged 5 to 12 years diagnosed with a depressive episode.

Methods: Fifteen participants, aged 5 to 12 , were assessed at a child and adolescent mental health center in Belo Horizonte, state of Minas Gerais, Brazil. All participants had a history of suicide attempt and were in a depressive episode at the time of assessment.

Results: Vulnerabilities related to the children themselves were self-harm, aggression, loss of an important family figure, sexual abuse, sexuality disorders, use of alcohol or other drugs, and illtreatment. Factors of family structure and dynamics found were psychiatric illness in family members, family conflict or violence, abandonment or rejection, history of suicidal behavior in family, parents users of alcohol and other drugs, and separated parents. Factors related to school were bullying, school difficulties/delays, high school performance, bad behavior, physical aggression, school dropout, and aggressiveness. The main methods used in suicide attempts were injury by sharp or blunt objects and intentional self-poisoning.

Conclusions: Psychiatric comorbidities and a previous history of disturbances in the family and at school are important factors to consider with relation to suicidal behavior by children with depressive episodes.
\end{abstract}

Keywords: Suicide, child, depressive disorder.

\section{Resumo}

Introdução: O comportamento suicida infantil está relacionado com vicissitudes específicas da infância, representadas por fatores de risco, incluindo fatores predisponentes, internos e ambientais.

Objetivo: Caracterizar o comportamento suicida em crianças de 5 a 12 anos com diagnóstico de episódio depressivo.

Métodos: Quinze participantes, com idades entre 5 e 12 anos, foram avaliados em um centro de saúde mental da infância e adolescência de Belo Horizonte, MG, Brasil. Todos os participantes tinham histórico de tentativa de suicídio e estavam em um episódio depressivo no momento da avaliação.

Resultados: As vulnerabilidades relacionadas às próprias crianças foram automutilação, agressão, perda de uma figura familiar importante, abuso sexual, distúrbios da sexualidade, uso de álcool ou outras drogas e maus-tratos. Em relação a estrutura e dinâmica familiar, foram encontrados fatores como doença psiquiátrica na família, conflito ou violência familiar, abandono ou rejeição, histórico de comportamento suicida na família, pais usuários de álcool e outras drogas e pais separados. Os fatores relacionados à escola foram assédio moral, dificuldades/atrasos escolares, bom desempenho escolar, mau comportamento, agressão física, abandono escolar e agressividade. Os principais métodos utilizados nas tentativas de suicídio foram lesões por objetos pontiagudos ou contundentes e autoenvenenamento intencional.

Conclusão: As comorbidades psiquiátricas e o histórico prévio de distúrbios na família e na escola são fatores importantes a serem considerados em relação ao comportamento suicida em crianças com episódios depressivos.

Descritores: Suicídio, criança, transtorno depressivo.

\footnotetext{
${ }^{1}$ Faculdade de Medicina, Universidade Federal de São João del Rei (UFSJ), Divinópolis, MG, Brazil. ${ }^{2}$ Programa de Residência Médica em Psiquiatria da Infância e Adolescência, Centro Psíquico da Adolescência e Infância (CEPAI/FHEMIG), Belo Horizonte, MG, Brazil. ${ }^{3}$ Programa de Pós-Graduação Mestrado e Residência Multiprofissional em Saúde do Adolescente, UFSJ, Divinópolis, MG, Brazil.

Submitted Dec 10 2018, accepted for publication Apr 072019.

Suggested citation: de Souza ALP, Segolin BW, Pessanha PB, Abreu TQA, Mino YEE, de Freitas FAC, et al. Characterization of suicidal behavior among children in a depressive episode: case series study. Trends Psychiatry Psychother. 2019;41(4):394-400. http://dx.doi.org/10.1590/2237-6089-2018-0111
} 


\section{Introduction}

Suicidal behavior in childhood is an action intended to harm oneself and includes suicide gestures, suicide attempts, and completed suicide. ${ }^{1}$ Suicide is a complex and multifaceted behavior, that has not yet been thoroughly examined among children. ${ }^{2}$ Suicide in childhood is not a random phenomenon. ${ }^{3}$ Suicide rates increase steeply from childhood to adolescence. Being a boy, living in a single-parent household, being an only or middle-born child, and living in rural regions are factors that have been associated with higher rates of suicide. There was no clear evidence for increases or decreases related to time of year. Additionally, the family and socioeconomic factors including type of household, birth order, and urbanity were associated with youth suicide in Switzerland. Therefore, these factors should be considered when designing a youth suicide prevention program. ${ }^{4}$

Suicide only occurs in vulnerable children. This vulnerability begins with parental mood disorders and impulsive aggression and a family history of suicide. Childhood affective and disruptive disorders and abuse are the most often reported psychiatric risk factors. ${ }^{3}$ Attempted suicide in children is a distressing subject for patients, their families, and health professionals, because it constitutes a transgression of the generalized conception of childhood as a stage of life free from worries and difficulties. This conception contributes to the scarcity of scientific production and few studies have been published on suicide in this age group. Furthermore, the condition is underreported, because the episode is usually recorded as an accident. ${ }^{5}$

Attempted suicide by children and adolescents is a manifestation of their suffering, which in general is the result of psychiatric disorders and of the difficulty in providing proactive treatment and assessment strategies. ${ }^{5}$ A family history of suicidal behavior is also one of the precursors of suicidal behavior in children, as are depression, suicidal ideation, behavioral problems, and child ill-treatment. ${ }^{6}$ The effect of childhood illtreatment and its relation to suicide is aggravated by the intergenerational transmission of abuse, so abuse is not only a risk factor for suicidal behavior for people who are abused as children, but also for their offspring. ${ }^{7}$ It is noteworthy that half of the children who committed suicide had diagnosed psychiatric illness, with mood disorders and social adjustments being the most relevant. ${ }^{3}$ Patients younger than 12 years usually attempt suicide for the first time with drug intoxication as the main method of perpetration. These children predominantly have anxiety and depression disorders, strongly associated with cognitive dysfunction as a factor of vulnerability. ${ }^{5}$ In Australia, $50 \%$ of children aged $10-14$ years and $57 \%$ of adolescents aged $15-17$ years who died by suicide had a mental disorder. ${ }^{8}$

It has been found that between 50 and $75 \%$ of children and adolescents who commit suicide have mood disorders and depressive disorders are the most prevalent in the suicidal behavior of children and adolescents, ${ }^{9,10}$ which is why we chose to study this association in the present study. Based on these considerations, this case series study aims to characterize suicidal behavior during depressive episodes in children aged 5 to 12 seen at a child and adolescent mental health center.

In addition to psychiatric factors, interactions between psychosocial, environmental, and contextual factors seem to be associated with suicide in childhood. Evidence-based knowledge of the myriad aspects of child suicide is crucial to understanding child suicide and to development of targeted suicide prevention. ${ }^{2}$ In Austria, in the period 1970-2001, epidemiological analyses indicated a decreasing trend in suicide rates among 10-19 year-olds. Suicide rates among minors in Austria continued to decrease during the period 2001-2014. Those findings help to inform the ongoing implementation of the Austrian Suicide Prevention Plan (SUPRA), which lists children and adolescents as a specific target population. ${ }^{11}$

\section{Materials and methods}

A case series study was carried out to describe the suicidal behavior of children with a diagnosis of a depressive episode. This method provides a detailed description of clinical cases containing important characteristics. ${ }^{12}$ A case series study can be used to search for a rare event, such as suicidal behavior among children, taking a specific subset of the topic addressed from a large sample. Reports and case series should aim to contribute additional benefits to current practices or chart possible new directions for research into a particular subject, in which a single or a few individuals may be representative, and/or propose innovative ways to approach a disease or treatment. They may also help formulate new hypotheses that can be tested using other study designs and, in certain situations, be an initial study for larger studies. ${ }^{13,14}$

This case series study was conducted at CEPAI (Centro Psíquico da Adolescência e Infância), in Belo Horizonte, the state capital of Minas Gerais, Brazil. The CEPAI is a referral center specialized in children's mental health care, to which cases of greater complexity in the state are referred. The project was approved by the Research Ethics Committees at the proposing 
institution (CAAE: 60757716.4.0000.5545) and the coparticipating institution (CAAE 60757716.4.3001.5119). Data collection was exclusively by review of the medical records of children with a history of suicide attempt and depressive episode and so signature of informed consent forms was not requested, but the Research Ethics Committees at the proposing institution and the co-participating institution approved the ethics compliance of the case descriptions.

At the CEPAI, records are organized by patients' psychiatric disorders, according to the ICD 10 classification. Diagnosis of depression is clinical, based on clear and well-defined criteria, derived from classification systems such as ICD-10 and SCID-5, performed using the Structured Clinical Interview for DSM-5. The SCID-5 is a semi-structured interview guide for making major DSM-5 diagnoses. Because diagnosis of depression is eminently clinical, diagnostic criteria and guidelines are important for its characterization, from the perspective of both the evaluator/patient pair and the multidisciplinary work during treatment.

For the study, charts selected according to the following inclusion criteria were analyzed: children from 5 to 12 years of age with a history of attempted suicide and depressive episode as the main diagnosis on admission to CEPAI, seen during the period from 2014 to 2016, at the Mood Disorders Clinic. The concept of childhood is somewhat imprecise. For the purpose of this research, we define children as under 13 years of age. ${ }^{15,16}$ Therefore, this case series study was conducted with children from 5 to 12 years of age.

A pre-established roadmap was developed to standardize data collection. Data collection was performed by actively searching for information present in the medical charts selected and registered at CEPAI. Information relevant to characterize the cases was extracted from written medical records (not electronic medical records). Those that recorded depressive episode as the main diagnosis on admission to the CEPAI were considered cases with a depressive episode. The researchers did not inspect cases with ICD depressive episodes.

\section{Results}

This case series study was based on the records of 9 girls and 6 boys whose main diagnosis was F32 (depressive episodes), with a mean age of 10 years. In 14 cases there was a record of suicidal ideation and there were no records of completed suicide. History of vulnerabilities in the series of 15 cases were analyzed. With regard to the children's personal histories, there were reports of self-harm in eight cases, aggression in seven, loss of an important family figure in six, sexual abuse in four, sexuality disorders in two, and use of alcohol or other drugs, and ill-treatment in one case each. In relation to family structure and dynamics, the most prevalent factor found was a family history of psychiatric illness, reported in eight cases. Family conflict or violence was described in five cases. There were four case each of abandonment or rejection, history of suicidal behavior in family, and parents users of alcohol and other drugs, and there were three cases in which parents were separated. Educational histories included four cases each of bullying, school difficulties/delays, and high school performance. Bad behavior, physical aggression, and school dropout were all reported in two cases, and aggressiveness was described on one record (Figure 1).

Regarding suicidal behavior, the methods used were categorized according to ICD-10 codes. Presence of suicidal ideation, number of suicide attempts, and deaths completed were all recorded. Records of suicidal behavior, including suicidal ideation, attempt, and suicide, in the series of 15 cases included suicidal ideation in 14 out of the 15 patients, at least one suicide attempt in all cases, and no records of completed suicide. The most common method of attempting suicide was use of sharp or blunt objects (X78, X79, ICD-10) reported in eight cases. Intentional self-poisoning ( $X 60$, X61, ICD-10) was recorded in seven cases; self-harm by unspecified means (X84, ICD-10) was recorded in three, jumping from a high place (X80, ICD-10) in two, and hanging, strangulation and suffocation (X70, ICD$10)$, jumping or lying before a moving object (a crane) (X81, ICD-10), and other specified means (X83, ICD$10)$ were each recorded in one case (Figure 1 ).

Analysis of the psychiatric histories of the series of 15 cases identified four cases of psychiatric hospitalization, although this number could be higher since there were medical charts that recorded requests for admission that could not be fulfilled because of a lack of available beds at the service. Some children with an indication for psychiatric hospitalization were referred for outpatient treatment due to lack of pediatric psychiatric beds for hospitalization, so this finding may be underestimated.

The main diagnoses at admission were a mild depressive episode (F32.0, ICD-10) in seven cases, a moderate depressive episode in four (F32.1, ICD10), a severe depressive episode with no psychotic symptoms in three (F32.2, ICD-10), and unspecified depressive episode (F32.9, ICD-10) in one case. There were records of varying degrees of depression during treatment. Since an attempt at suicide is modifying the severity of depressive symptoms, it is understood 
that the psychiatric comorbidities present in the cases studied may explain the presence of mild and moderate depressive episodes.

The classes of drugs prescribed included antidepressants, antipsychotics, antimanics, antihypertensives, antihistamines, antiparkinsonians, and benzodiazepines, with a greater emphasis on antidepressants, which were used in all records in the series of 15 cases. Psychiatric comorbidities found were: multiple drug use (F19, ICD-10), bipolar affective disorder and unspecified mood disorder (F31.4, F39, ICD-10), obsessive-compulsive disorder, adjustment disorders, and dissociative disorders (F42-F44, ICD10), bulimia nervosa, atypical form (F50.3, ICD-10), mild mental retardation (F70, ICD-10), and conduct disorders (F91, ICD-10). Comorbidities have been shown to be an important factor in suicidal behavior in children (Figure 1).

\section{Discussion}

Analysis of the history of vulnerabilities highlighted the relevance of the association between self-harm and suicide attempts, since this was the most frequent element in the personal histories of the children in the cases studied. A history of non-suicidal self-harm is associated with an increased likelihood of suicide attempt and is a risk factor for suicidal behavior. ${ }^{17,18}$ One systematic review showed a positive association between parental loss and suicidal behavior, ${ }^{19}$ as was observed in six of the cases studied. Death of parents during childhood was associated with a prolonged risk of suicide among children whose father had died of suicide or other causes in a cohort study in three Scandinavian countries. ${ }^{20}$ The consequences of parental death in childhood are far-reaching, and suicide risk trajectories can be influenced by early life conditions.

\begin{tabular}{|c|c|c|c|c|c|c|c|c|c|c|c|c|c|c|c|}
\hline & C1 & $\mathbf{C 2}$ & C3 & C4 & C5 & C6 & C7 & $\mathbf{C 8}$ & C9 & C10 & C11 & C12 & C13 & C14 & C15 \\
\hline Sexual abuse & & & $\mathrm{Y}$ & & & & & $\mathrm{Y}$ & & & & $\mathrm{Y}$ & & $\mathrm{Y}$ & \\
\hline Ill-treatment & & & & & & & & $\mathrm{Y}$ & & & & & & & \\
\hline Self-harm & $\mathrm{Y}$ & & $\mathrm{Y}$ & $\mathrm{Y}$ & $\mathrm{Y}$ & & & $\mathrm{Y}$ & & Y & & & Y & & $\mathrm{Y}$ \\
\hline Sexuality disorders & & $\mathrm{Y}$ & & & & & & & & $\mathrm{Y}$ & & & & & \\
\hline $\begin{array}{l}\text { Loss of important family } \\
\text { figure }\end{array}$ & & & & $\mathrm{Y}$ & & $\mathrm{Y}$ & Y & & & & Y & & & Y & $\mathrm{Y}$ \\
\hline Aggressive behavior & & Y & $\mathrm{Y}$ & & $\mathrm{Y}$ & & & $\mathrm{Y}$ & & & $\mathrm{Y}$ & $\mathrm{Y}$ & $\mathrm{Y}$ & & \\
\hline Use of alcohol or other drugs & & & $\mathrm{Y}$ & & & & & & & & & & & & \\
\hline Divorced parents & Y & & & Y & & & & & & & $\mathrm{Y}$ & & & & \\
\hline Abandonment or rejection & & Y & & $\mathrm{Y}$ & & & & $\mathrm{Y}$ & & & & & $\mathrm{Y}$ & & \\
\hline $\begin{array}{l}\text { History of suicidal behavior } \\
\text { in family }\end{array}$ & $\mathrm{Y}$ & & & & Y & & Y & & Y & & & & & & \\
\hline $\begin{array}{l}\text { Psychiatric illness in family } \\
\text { members }\end{array}$ & & & $\mathrm{Y}$ & $\mathrm{Y}$ & $\mathrm{Y}$ & & & & Y & $\mathrm{Y}$ & & $\mathrm{Y}$ & & Y & $\mathrm{Y}$ \\
\hline Family conflict or violence & Y & & & $\mathrm{Y}$ & & & & & & $\mathrm{Y}$ & & & & Y & Y \\
\hline $\begin{array}{l}\text { Parents users of alcohol and } \\
\text { other drugs }\end{array}$ & $\mathrm{Y}$ & & & $\mathrm{Y}$ & & & Y & $\mathrm{Y}$ & & & & & & & \\
\hline Bullying & $\mathrm{Y}$ & $\mathrm{Y}$ & & & $\mathrm{Y}$ & & & & & $\mathrm{Y}$ & & & & & \\
\hline Bad behavior & & & & & & & & & & & $\mathrm{Y}$ & & $\mathrm{Y}$ & & \\
\hline Physical aggression & & Y & & & & & & & & Y & & & & & \\
\hline Aggressive behavior & & & & & & & & & & & & $\mathrm{Y}$ & & & \\
\hline School difficulties/delays & & Y & & & $\mathrm{Y}$ & & & & & & $\mathrm{Y}$ & & & Y & \\
\hline High school performance & & & & & & & & & $\mathrm{Y}$ & $\mathrm{Y}$ & & & $\mathrm{Y}$ & & $\mathrm{Y}$ \\
\hline School dropout & & & $\mathrm{Y}$ & & & & & & & & & & & Y & \\
\hline Suicidal ideation & $\mathrm{Y}$ & Y & & $\mathrm{Y}$ & Y & $\mathrm{Y}$ & $\mathrm{Y}$ & $\mathrm{Y}$ & $\mathrm{Y}$ & $\mathrm{Y}$ & $\mathrm{Y}$ & $\mathrm{Y}$ & $\mathrm{Y}$ & $\mathrm{Y}$ & $\mathrm{Y}$ \\
\hline Suicidal attempt & 3 & M & 5 & M & M & 1 & 1 & 4 & M & 1 & 1 & 2 & 3 & 3 & 2 \\
\hline Method used* & $\begin{array}{l}X 61 \\
X 78 \\
X 79\end{array}$ & $x 84$ & $\begin{array}{l}X 60 \\
\times 61 \\
\times 78 \\
X 79 \\
\times 84\end{array}$ & $\begin{array}{l}X 78 \\
X 79\end{array}$ & $\begin{array}{l}X 78 \\
X 79\end{array}$ & $x 60$ & $x 60$ & $\begin{array}{l}x 70 \\
x 78 \\
X 79 \\
x 83\end{array}$ & $\begin{array}{l}X 78 \\
X 79\end{array}$ & $x 80$ & $x 60$ & $\begin{array}{l}X 61 \\
X 78 \\
X 79\end{array}$ & X84 & $\begin{array}{l}X 80 \\
X 78 \\
X 79 \\
x 81\end{array}$ & $\mathrm{x} 61$ \\
\hline Admission diagnosis* & F32.2 & F32.1 & F32.0 & F32.0 & F32.0 & F32.2 & F32.2 & F32.9 & F32.0 & F32.0 & F32.0 & F32.0 & F32.1 & F32.1 & F32.1 \\
\hline Degrees of depression* & & & F32.2 & F32.1 & F32.9 & & & & & $\begin{array}{l}\text { F32.1 } \\
\text { F32.2 }\end{array}$ & & & & F32.2 & \\
\hline Other psychiatric diagnoses* & F43.2 & $\begin{array}{c}\text { F43.2 } \\
\text { F50.3 } \\
\text { F70 } \\
\text { F91.3 } \\
\text { Z60 }\end{array}$ & $\begin{array}{c}\text { F19 } \\
\text { F45.1 } \\
\text { F91.1 } \\
\text { F91.2 } \\
\text { Z61.5 }\end{array}$ & $\mathrm{Z} 60$ & F43.2 & & & & & & F91.3 & F39 & F42.2 & $\begin{array}{c}\text { F31.8 } \\
\text { F31.4 } \\
\text { F31 } \\
\text { F39 } \\
\text { F91.2 }\end{array}$ & $\begin{array}{l}\text { F39 } \\
\text { F44.3 } \\
\text { F44.5 }\end{array}$ \\
\hline
\end{tabular}

Figure 1 - History of vulnerability, psychiatric history, and suicidal behavior. $C=$ Case; $Y=$ Yes; M = Multiple. ${ }^{*}$ According to ICD-10. 
Preventive efforts are challenging because of the highly complex interactions among family members and the long-term risk profiles observed among the children. Therefore, early mitigation of suffering may reduce the risk of suicidal behavior among children whose fathers die during their childhood. ${ }^{20}$

Alcohol consumption, although reported in only one case, appears in the literature as an important risk factor. Alcohol is associated with risk, impulsivity, and aggressive behavior, increasing the risk of suicidal behavior. $^{21}$

In relation to family dynamics and structure, five cases were reported of family conflict or violence and in four cases parents were users of alcohol and drugs. In this regard, the literature shows that dysfunctional families, family conflict, and parents who use alcohol and other drugs are associated with suicidal behavior in children. ${ }^{21,22}$ Conflicts between parents and children appear to be a major precipitating factor for children and more frequent compared to adolescents. ${ }^{2}$ Family conflict was the most frequent event in the 10 to 14 years age group, while relationship problems were most frequent in the 15 to 19 years and 20 to 24 years age groups, when suicides of children, adolescents, and young adults were compared. ${ }^{8}$

A history of suicidal behavior in the family was reported in one quarter of the cases studied and psychiatric illness in half of the cases. A study of the relationships between genetic and family environment effects and suicide attempts showed that genetic influences contribute to the risk of suicide attempts, as was found in the present study. ${ }^{23} \mathrm{~A}$ family history of suicide is still the highest risk factor for suicidal behavior, illustrating that a parental history of suicide attempt confers an increased likelihood of the offspring attempting suicide, confirming the relationship found in the cases under analysis. ${ }^{24-26}$ Along the same lines, it also appears that paternal psychopathology is an important risk factor for attempted suicide in the offspring. ${ }^{27}$ Psychopathologies in the family, such as parental mood and personality disorders and substance abuse, have been demonstrated to increase child risk of non-fatal suicidal behavior. ${ }^{2}$ Out of 54 studies identified for a review, nine studies indicated a significantly increased risk of offspring suicide-related thoughts suicide attempts and suicide among those exposed to maternal suicide attempts and suicide in childhood or adolescence. In the remaining 45 studies with a higher risk, this association persisted. The majority of studies $(67 \%)$ did not confirm that the exposure occurred in the offspring's childhood or adolescence, but findings were suggestive of a mediating effect of offspring psychiatric symptoms. ${ }^{28}$
The most frequently reported factors related to school history were bullying and school difficulties. As described in the literature, involvement in bullying and being a victim of aggression are associated with an increased risk of suicide.26,27 Family and school are the most important social institutions in the lives of children. A systematic review lists bullying, negative peer pressure, and perceived or actual school performance problems as psychosocial school-related factors associated with child suicide. ${ }^{2}$ School difficulties/failures are identified as one of the causes for ideation and attempted suicide among children, ${ }^{21-25}$ underscoring the findings from the cases under analysis.

In this study, it was observed that suicidal ideation was described in 14 of the cases studied. A suicide attempt, which is one of the criteria for inclusion of cases in this study, was present in all medical records analyzed. There were cases with one, two, three, four, and five attempts. Multiple suicide attempts were reported in four of the medical records, all of them female. The method most used in the attempts was intentional self-harm by sharp and blunt objects, followed by intentional self-poisoning. This information is very much in line with the international literature, which presents intentional self-poisoning followed by wrist cutting and hanging as the most prevalent methods in child suicide attempts. ${ }^{21,25}$ Methods were generally similarly distributed between boys and girls, except in intentionally self-harming injury by sharp and blunt objects, of which there were six female cases compared to two male cases. In a review of 12 studies of suicide in children aged 14 years and younger, 10 studies identified the predominant suicide method and 5 of these found that children most frequently used hanging. ${ }^{2}$

Analysis of the psychiatric histories of the children selected for the case study revealed, that the drug class most often used for treatment was antidepressants, of which fluoxetine was the most common drug. This was used by all patients. In fact, this drug is the only drug approved by the FDA for use in children and adolescents with depression and is, therefore, the drug of choice, indicated for treatment in the latest American Academy of Pediatrics (AAP) guidelines, published in 2018.29

Psychological autopsy studies indicate an association between suicide in children and adolescents and psychiatric disorders in $81-95 \%$ of cases and psychiatric comorbidities in 51 to $85 \%$ of the cases. ${ }^{9}$ All the cases studied had diagnoses of depressive episodes (in accordance with the inclusion criteria) and 9 out of 15 had other psychiatric comorbidities. Mood disorders are the psychiatric disorders most associated with suicide, and this association is 
more common among girls, ${ }^{9}$ as evidenced in this study. In addition to the main diagnosis of F32, girls had a greater number of other mood disorders as comorbidities.

It is known that mental disorders are among the strongest indicators of suicide attempts. However, little is known about which disorders are exclusively associated with suicidal behavior due to high levels of psychiatric comorbidity. Research on associations between individual disorders and subsequent suicidal behavior (suicidal ideation, plans, and attempts) using data from the National Comorbidity Survey Replication underscores the importance of carefully considering comorbidity in the study of suicidal behavior, clarifying the ways in which different types of mental disorders can contribute to the risk of suicidal behavior. ${ }^{30}$

International studies point to an association between psychoactive substance use and suicide, ${ }^{9,31}$ which was found in one of the cases studied. Substance use may mediate depression and suicidal behavior because of its disinhibiting power or else be capable of generating feelings of hopelessness and impotence. ${ }^{31}$

Dissatisfaction with body image is also identified as a risk factor ${ }^{31}$ and was found in one case. Psychiatric hospitalizations were reported in $33 \%$ of the patients, that is, in five of the 15 cases, which is higher than the average rate of hospitalizations found in the literature, currently at around $20 \%$. $^{32}$ This difference can be explained by the location of the patients studied in this study. CEPAI is a center specialized in the care of children and adolescents with psychiatric disorders and a state-level referral center for cases of greater complexity, with an appropriate facility for hospitalization of children when necessary. Since all the children studied in this project were treated at CEPAI, those who had an indication for hospitalization were admitted to the service.

The main limitations of this study are those inherent to case reports and series; conclusions are based on a few cases and they do not have representative sampling and methodology capable of validating causal association. ${ }^{12}$ There is also no control group for comparison, they do not quantify the prevalence in the population and the methodology for diagnosis and intensity of symptoms is not standardized. ${ }^{12}$ Another limitation of the study is that cases that presented to the emergency service or those transferred directly to the hospital were not included. It is therefore suggested that all results be interpreted carefully. It is hoped that the present article will encourage production of more studies on suicidal behavior in this age group, which are still very scarce.

\section{Conclusion}

Comorbidities and history of vulnerability (personal, family, and school history) are important factors in suicidal behavior in children diagnosed with a depressive episode. The vulnerabilities of these children were related to personal experience of violence, loss of an important family figure, sexuality disorders and use of alcohol or other drugs; family psychiatric illnesses, conflict, abandonment, suicidal behavior, use of alcohol and other drugs; and, at school, bullying, school difficulties or delays, or dropping out of school. Sharp and blunt objects and intentional self-poisoning were the main methods used in suicide attempts by children with a diagnosis of a depressive episode. It is concluded that measures need to be established to ensure the care and support of vulnerable children. Approaches should be focused on mitigating these patients' histories of vulnerability, understanding their suicidal behavior, and treating their psychiatric disorders, in the context of multidisciplinary treatment and with a support network (family/school/community).

\section{Disclosure}

No conflicts of interest declared concerning the publication of this article.

\section{References}

1. Kuczynski E. Suicídio na infância e adolescência. Psicol USP. 2014;25:246-52.

2. Soole R, Kõlves K, De Leo D. Suicide in children: a systematic review. Arch Suicide Res. 2015;19:285-304.

3. Dervic K, Brent DA, Oquendo MA. Completed suicide in childhood. Psychiatr Clin North Am. 2008;31:271-91.

4. Steck N, Egger M, Schimmelmann BG, Kupferschmid S; Swiss National Cohort. Suicide in adolescents: findings from the Swiss National cohort. Eur Child Adolesc Psychiatry. 2018;27:47-56.

5. Vásquez-Rojas R, Quijano-Serrano M. Cuando el intento de suicidio es cosa de niños. Rev Colomb Psiquiatr. 2013;43(S1):3646.

6. Zalsman G, Levy T, Shoval G. Interaction of child and family psychopathology leading to suicidal behavior. Psychiatr Clin North Am. 2008;31:237-46.

7. Hawton K, HeeringenKv. Suicide. The Lancet. 2009;373:137281.

8. Soole $\mathrm{R}$, Kolves $\mathrm{K}$, De Leo D. Factors related to childhood suicides: analysis of the Queensland Child Death Register. Crisis. 2014;35:292-300.

9. Argemí S, Cobo J, Pujol G, Bartoli D, Aldecoa V, García M. Características y evolución de las urgencias psiquiátricas infanto juveniles en un servicio general de urgencias pediátricas hospitalarias. Acta Pediatr Esp. 2010;68:547-53.

10. Thiengo DL, Cavalcante MT, Lovisi GM. Prevalência de transtornos mentais entre crianças e adolescentes e fatores associados: uma revisão sistemática. J Bras Psiquiatr. 2014;63:360-72.

11. Laido Z, Voracek M, Till B, Pietschnig J, Eisenwort B, Dervic K, et al. Epidemiology of suicide among children and adolescents in Austria, 2001-2014. Wien Klin Wochenschr. 2017;129:121-8. 
12. Parente RCM, Oliveira MAP, Celeste RK. Relatos e série de casos na era da medicina baseada em evidência. Braz J Video-Surg. 2010;3:67-70.

13. Albrecht J, Meves A, Bigby M. Case reports and case series from Lancet had significant impact on medical literature. J Clin Epidemiol. 2005;58:1227-32.

14. Jenicek M. Clinical case reports and case series research in evaluating surgery. Med Sci Monit. 2008;14:149-62.

15. Kohan W. Devir-criança da filosofia: infância da educação. São Paulo: Autentica; 2018.

16. Nascimento CT, Brancher VR, Oliveira VF. A construção social do conceito de infância: algumas interlocuções históricas e sociológicas. Contexto Educ. 2008, 23:47-63.

17. Ribeiro JD, Franklin JC, Fox KR, Bentley KH, Kleiman EM, Chang $B P$, et al. Self-injurious thoughts and behaviors as risk factors for future suicide ideation, attempts, and death: a meta-analysis of longitudinal studies. Psychol Med. 2016;46:225-36.

18. Victor SE, Styer D, Washburn JJ. Characteristics of nonsuicidal self-injury associated with suicidal ideation: evidence from a clinical sample of youth. Child Adolesc Psychiatry Ment Health. 2015;9:1-8.

19. Serafini G, Muzio C, Piccinini G, Flouri E, Ferrigno G, Pompili M, et al. Life adversities and suicidal behavior in young individuals: a systematic review. Eur Child Adolesc Psychiatry, 2015;24:142346.

20. Guldin MB, Li J, Pedersen HS, Obel C, Agerbo E, Gissler M, et al. Incidence of suicide among persons who had a parent who died during their childhood: a population-based cohort study. JAMA Psychiatry. 2015;72:1227-34.

21. González-Castro TB, Tovilla-Zárate CA Hernández-Díaz $Y$ Juárez-Rojop IE, León-Garibay AG, Guzmán-Priego CG, et al. Characteristics of Mexican children and adolescents who died by suicide: A study of psychological autopsies. J Forensic Leg Med. 2017;52:236-40.

22. Mekaoui N, Karboubi L, Ouadghiri FZ, Dakhama BSB. Epidemiological aspects of suicide attempts among Moroccan children. Pan Afr Med J. 2016;24:112.

23. Petersen L, Sørensen TI, Kragh P, Mortensen PB, Hawton K. Genetic and familial environmental effects on suicide attempts: a study of Danish adoptees and their biological and adoptive siblings. J Affect Disord. 2014;155:273-7.
24. Brent DA, Melhem NM, Oquendo M, Burke A, Birmaher B, Stanley $B$, et al. Familial pathways to early-onset suicide attempt: a 5.6year prospective study. JAMA Psychiatry. 2015;72:160-8.

25. Lopez-Castroman J, Jaussent I, Beziat S, Genty C, Olié E, de Leon-Martinez $\mathrm{V}$, et al. Suicidal phenotypes associated with family history of suicidal behavior and early traumatic experiences. J Affect Disord. 2012;142:193-9.

26. Arangoab A, Opperman KJ, Gipson PY, King CA. Suicidal ideation and suicide attempts among youth who report bully victimization, bully perpetration and/or low social connectedness. J Adolesc. 2016;51:19-29.

27. Conner KR, Bossarte RM, Lu N, Kaukeinen K, Chan G, Wyman $P$, et al. Parent and child psychopathology and suicide attempts among children of parents with alcohol use disorder. Arch Suicide Res. 2014;18:117-30.

28. Goodday SM, Shuldiner J, Bondy S, Rhodes AE. Exposure to parental psychopathology and offspring's risk of suicide-related thoughts and behaviours: a systematic review. Epidemiol Psychiatr Sci. 2017;28:179-90.

29. Zainum K, Cohen MC. Suicide patterns in children and adolescents: a review from a pediatric institution in England. Forensic Sci Med Pathol. 2017;13:115-22.

30. Nock MK, Hwang I, Sampson NA, Kessler RC. Mental disorders, comorbidity and suicidal behavior: results from the National Comorbidity Survey Replication. Mol Psychiatry. 2010;15:86876.

31. Zuckerbrot RA, Cheung A, Jensen PS, Stein RK, Laraque D. Guidelines for Adolescent Depression in Primary Care (GLADPC): Part II. Treatment and ongoing management. Pediatrics. 2018;141:e20174082.

32. $\mathrm{O}^{\prime}$ Connell KL. Child and adolescent suicide. J Child Adolesc Psychiatr Nurs. 2012;25:111-2.

\section{Correspondence:}

Nadja Cristiane Lappann Botti

Universidade Federal de São João Del Rei

Av. Sebastião Gonçalves Coelho, 400, sala 301.1, bloco D, Bairro Chanadour

35501-296 - Divinópolis, MG - Brazil

E-mail: nadjaclb@terra.com.br 